Piet Vanhaesebrouck · Alain G. Verstraete

Claudine De Praeter · Koenraad Smets

Alexandra Zecic $\cdot$ Margarita Craen

\title{
Transplacental passage of a nonionic contrast agent
}

Received: 4 January 2005 / Accepted: 16 February 2005 / Published online: 30 March 2005

(C) Springer-Verlag 2005

\begin{abstract}
We report the presence of iopromide in the bowel and urine of a preterm infant, born 10 days after intravenous administration of the nonionic monomer to his mother. Excessive urinary iodine excretion and borderline hyperthyrotropinaemia were observed in the infant. Moreover, crossing of the fetal blood-brain barrier was demonstrated by detection of the angiographic material in CSF and thus direct fetal neurotoxic effects cannot be excluded. Conclusion: These widely used contrast media may cross the placenta and accumulate in various fetal tissues in significant amounts causing possible neonatal toxicity. Therefore the perinatal safety of these diagnostic agents should at least be questioned.
\end{abstract}

Keywords Iopromide - Nonionic monomer - Thyroid · Transplacental passage $\cdot$ Urinary iodine

\section{Introduction}

Although the newer nonionic contrast media used for conventional X-ray and MRI studies are well-tolerated in humans, very little is known about placental transfer and the possible effects on the fetus [7]. In two animal models no placental passage of nonionic compounds

P. Vanhaesebrouck $(\bowtie) \cdot$ C. De Praeter $\cdot$ K. Smets $\cdot$ A. Zecic Department of Neonatology,

Ghent University Hospital, De Pintelaan 185,

9000 Ghent, Belgium

E-mail: piet.vanhaesebrouck@UGent.be

Tel.: + 32-9-2403527

Fax: + 32-9-2406105

A. G. Verstraete

Department of Clinical Biochemistry,

Ghent University Hospital, Ghent, Belgium

M. Craen

Department of Paediatric Endocrinology,

Ghent University Hospital,

Ghent, Belgium could be detected $[2,16]$; however, animal studies are not always predictive of human response and adequate, wellcontrolled studies in humans have not been done. In one recently published report, placental transfer of iohexol (Omnipaque) within $24 \mathrm{~h}$ was demonstrated postnatally by fetal gut opacification in a human twin pregnancy [13]. We report the presence of iopromide not only in the bowel but also in urine and CSF together with transient mild thyroid dysfunction in a preterm infant after intravenous administration of the contrast medium to the mother 10 days before birth.

\section{Case report}

An obese (body weight $107 \mathrm{~kg}$ ) 26-year-old primipara was transferred to the maternity ward at 27 weeks of gestation because of threatening preterm labour. Tocolysis was initiated. Two days later, because of acute dyspnoea and low oxygen saturation, the attendant radiologist deemed the performance of pulmonary CT angiography necessary to exclude pulmonary embolism. A high dose of the nonionic, iodinated contrast medium iopromide (200 ml Ultravist-370, Schering) was given intravenously. No lung embolism could be detected. Ten days after the CT angiogram, membranes ruptured spontaneously and $1 \mathrm{~h}$ later a preterm boy was born vaginally at 29 weeks' gestation. Apgar scores were 7 and 9 at 1 and $5 \mathrm{~min}$, respectively. Birth weight was $1491 \mathrm{~g}$. The baby had only mild respiratory distress. No goitre was observed. A plain abdominal X-ray film performed on day 1 showed intraluminal gastrointestinal opacifications consistent with the presence of radiographic contrast material. This unexpected finding was confirmed by a lateral view film (Fig. 1). Convulsions or abnormal neurological behaviour were not observed. The iopromide level was $0.13 \mathrm{ng} / \mathrm{ml}$ in a urine sample on day 8. Iopromide concentration in CSF on day 9 was $0.1 \mathrm{ng} / \mathrm{ml}$. The contrast monomer was no longer detectable in a urine sample on day 12. Iopromide was determined in CSF and urine by a method modified 
from those of Hirsch et al. [10] and Putschew et al. [14]. Liver and renal function tests, ionogram, as well as clotting screening tests were all normal. Urinary iodine concentration on day 8 of life was $880 \mu \mathrm{g} / 1$ (normal reference value $<200 \mu \mathrm{g} / \mathrm{l})$. Iodine containing solutions were not used in the delivery room or during neonatal care. Serum FT4 levels were 1.1 and $1.2 \mathrm{ng} / \mathrm{dl}$ on days 7 and 31 of life, respectively (reference range $0.9-1.7 \mathrm{ng} /$ dl). The corresponding levels of TSH were 2.7 and $6.2 \mathrm{mU} / 1(95 \%$ age-specific confidence intervals 0.45 $4.12 \mathrm{mU} / \mathrm{l})$. Apart from a persistent apnoea syndrome, the further hospital course was uneventful. On follow-up at the corrected age of 4 months, the child showed normal neurodevelopment, although some axial hyperextensive posturing was suspected. At that time, cerebral ultrasound and thyroid function were normal (serum FT4 $1.3 \mathrm{ng} / \mathrm{dl}$ and TSH $2.3 \mathrm{mU} / \mathrm{l})$.

\section{Discussion}

Transplacental passage and fetal uptake of an ionic agent such as diatrizoate has been demonstrated in early human pregnancy [5]. Neonatal intestinal opacification secondary to transplacental passage of an ionic contrast medium (Renografin-60) after maternal excretory urography was first documented by Kelleher et al. in 1979 [11].

In rodent and non-rodent animal models, nonionic monomers such as iobitridol, iohexol and iopromide administered in comparable doses as used clinically in conventional X-ray imaging studies were shown to be rapidly excreted with no clear passage across the placenta and no retention in amniotic fluid nor fetal tissues $[2,16]$. However, one recent report documented placental transfer of a nonionic contrast medium by the radiographic appearance of contrast material in the intestines of preterm twin fetuses after intravenous administration of iohexol to the pregnant mother for angiography $17 \mathrm{~h}$ before birth [13]. The present report confirms the transplacental passage of another nonionic monomer administered to a pregnant mother 10 days before birth.
The contrast agent can pass across the placenta into the fetal circulation, be excreted by the fetal kidneys into the amniotic fluid and can be swallowed by the fetus. Alternatively, contrast medium from the maternal circulation may equilibrate directly into the amniotic fluid by passive intramembranous diffusion and this fluid is then also swallowed by the fetus [9].

Iopromide is reported not to pass the blood-brain barrier (Schering documentation); however, in our patient, iopromide could still be detected in CSF 20 days after contrast administration to the mother. It is known that intravascular contrast agents can occasionally cause selective osmotic disruption of the blood-brain barrier and may induce signs of direct neurotoxicity such as transitory cortical blindness, convulsions, apnoea and sedation [15]. Iopromide is not indicated for intrathecal use. When the agent is given intrathecally, serious adverse reactions have occurred, including death, convulsions, cerebral haemorrhage and coma [3].

Previous studies have shown that preterm infants are very sensitive to an iodine load with a significant risk of hypothyroidism [12]. Ares et al. [1] reported that thyroid complications due to iodine exposure should be suspected in those premature infants with urinary iodine concentrations greater than $200 \mu \mathrm{g} / \mathrm{l}$. The iodine overload and mild, albeit transient, neonatal hyperthyrotropinaemia put our patient at risk of subclinical hypothyroidism at a critical age for the normal development of the nervous system in later infancy [4]. However, it is reassuring that (transient) hypothyroidism or hyperthyrotropinaemia were not detected in the patients of Dembinski et al. [6] receiving iopromide postnatally for diagnostic imaging of non-radio-opaque central silastic catheters. Degradation of iopromide produces about $0.06 \mathrm{mg}$ of free readily absorbable iodide per $100 \mathrm{ml}$ contrast medium, which is significantly less than ionic and also most other nonionic agents. The mother is also at risk for hypothyroidism due to the Wolff-Chaikoff effect (blockade of iodide absorption by the thyroid gland) induced by the acute iodine overload. Iodine-containing contrast media can induce transient subclinical hypothyroidism in adult euthyroid patients

Fig. 1 Anteroposterior (A) and lateral view (B) X-ray films of the abdomen on day 1 of life showing the presence of contrast material (arrows)
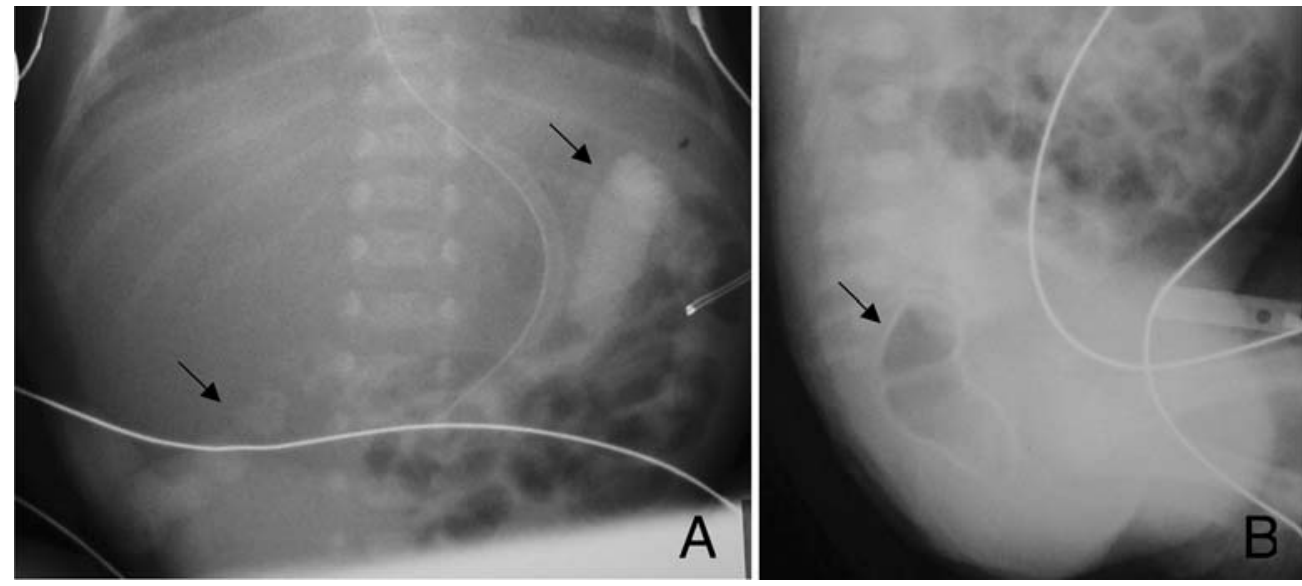
[8]. Therefore our patient and his mother will be routinely monitored.

The potential hazards of fetal exposure to radiographic non-ionic contrast agents should be further investigated and for the time being their perinatal safety should still be questioned. In the absence of specific studies, it is recommended that when no safer alternative exists, these products should be used very cautiously in pregnant women.

\section{References}

1. Ares S, Pastor I, Quero J, Morreale de Escobar G (1995) Thyroid complications, including overt hypothyroidism, related to the use of non-radiopaque silastic catheters for parenteral feeding in prematures requiring injection of small amounts of an iodinated contrast medium. Acta Paediatr 84: 579-581

2. Bourrinet P, Dencausse A, Havard P, Violas X, Bonnemain B (1995) Transplacental passage and milk excretion of iobitridol. Invest Radiol 30: 156-158

3. Caillé JM, Allard M (1988) Neurotoxicity of hydrosoluble iodine contrast media. Invest Radiol 23: S210-S212

4. Calaciura F, Motta RM, Miscio G, Fichera G, Leonardi D, Carta A, Trischitta V, Tassi V, Sava L, Vigneri R (2002) Subclinical hypothyroidism in early childhood: a frequent outcome of transient neonatal hyperthyrotropinemia. J Clin Endocrinol Metab 87: 3209-3214

5. Dean PB (1977) Fetal uptake of an intravascular radiologic contrast medium. Fortschr Geb Rontgenstrahlen Nuklearmed Erganzungsbd 127: 267-270

6. Dembinski J, Arpe V, Kroll M, Hieronimi G, Bartmann P (2000) Thyroid function in very low birth weight infants after intravenous administration of the iodinated contrast medium iopromide. Arch Dis Child Fetal Neonatal Ed 82: F215-F217
7. Faykus MH, Cope C, Athanasoulis C, Druy EM, Hedgcock M, Miller FJ, Bron K (1994) Double-blind study of the safety, tolerance, and diagnostic efficacy of iopromide as compared with iopamidol and iohexol in patients requiring aortography and visceral angiography. Invest Radiol 29: 98-101

8. Gartner W, Weissel M (2004) Do iodine-containing contrast media induce clinically relevant changes in thyroid function parameters of euthyroid patients within the first week? Thyroid 14: 521-524

9. Gilbert WM, Eby-Wilkens E, Tarantal AF (1997) The missing link in rhesus monkey amniotic fluid volume regulation: intramembranous absorption. Obstet Gynecol 89: 462-465

10. Hirsch R, Ternes TA, Lindart A, Haberer K, Wilken RD (2000) A sensitive method for the determination of iodine containing diagnostic agents in aqueous matrices using LCelectrospray-tandem-MS detection. Fres J Anal Chem 366: 835-841

11. Kelleher J, Feczko PJ, Radkowski MA, Griscom NT (1979) Neonatal intestinal opacification secondary to transplacental passage of urographic contrast medium. Am J Roentgenol 132: 63-65

12. L'Allemand D, Gruters A, Beyer P, Weber B (1987) Iodine in contrast agents and skin disinfectants is the major cause for hypothyroidism in premature infants during intensive care. Horm Res 28: 42-49

13. Moon AJ, Katzberg RW, Sherman MP (2000) Transplacental passage of iohexol. J Pediatr 136: 548-549

14. Putschew A, Schittko S, Jekel M (2001) Quantification of triiodinated benzene derivatives and X-ray contrast media in water samples by liquid chromatography-electrospray tandem mass spectrometry. J Chromatog A 930: 127-134

15. Schulte-Altedorneburg G, Rüb K, Scheglmann K (2004) Simultaneous ischemic and neurotoxic brain damage after coronary angiography. Neurol Res 26: 79-82

16. Tauber U, Mutzel W, Schulze P (1989) Whole body autoradiographic distribution studies on nonionic X-ray contrast agents in pregnant rats. Fortschr Geb Röntgenstrahlen Nuklearmed Ergänzungsbd 128: 215-219 